\title{
Indice general de autores de los números 1-40 1967-1977
}

Aberastury, Marcelo. Asia Oriental y Meridional y el Pacífico: inicios de 1972. Año v, No I7 (enero-marzo, 1972) .

Acosta, Mercedes y ViLas, Carlos María. Santo Domingo y Checoslovaquia en la politica de bloques. Año If, NQ 8 (cnero-marzo, 1969).

AFtalion, Marcelo E. La política exterior norteamericana $y$ América Latina. Año $\mathrm{x}$, No 37 (enero-marzo, 1977).

Almeyda, Clodomiro. Las olas y la crisis política de América Latina. Año I, Ne 3-4 (octubre, 1967-marzo, 1968).

Arlujo Castro, Josć $\Lambda$, de. El continente americano dentro de la problemática mundial. Año v, Ne 20 (octubre-dicicmbre, 1972) .

AzIz, Sartaj. Los verdaderos problemas de la crisis de alimentos. Año viI, No 30 (abril-junio, 1975).

Baltra, Alberto. América Latina y la Segunda unctad. Año II, No 8 (cnero-marzo, 1969).

BALL, W. MacMahon. Australia en el Pacífico. Año v, No 20 (octubre-diciembre, 1972).

BAmmirka, Vania. La revolución cultural y el marxismo. Año II, No 7 octubre-diciembre, 1968).

Bergsten, C. Fred. Relaciones económicas entre Estados Unidos y Latinoamérica: la estructura interna. cional y algunos enfoques posibles. Año vir, No 31 , julio-scptiembre, 1975) .

Bernstein, Enrique. Situación política en víspera de mayo de 1968. Año v, No 19 (julio-septiembre, 1972).
BODENHEMIR, Susanne. La crisis del mo. vimiento socialdemócrata en Amévica Latina. Año Iv, No 12 (eneromarzo, 1970).

BOGNAR, Jozsef. Reforma económica en Fungra. Año II, No 10 (julio-septiembre, 1969).

Bult, Hedley, Las relaciones internacionales como ocupación académica. Año vir, $N^{\top} 928$ (octubre-diciembre, 1974).

Burton, J. W. No-alineación y política mundial contemporánca. Año III, No 9 (abril-junio, 1969).

BYтн, James, Niugini: una nueva nación cupriffera en el Pacifico se acerca a su independencia. Año $\mathrm{r}$, No 22 (abril-junio, 1973).

Cadena, Cecilia y Joxe, Alain. Armamentismo dependiente: Caso latinoamericano. Año $\mathrm{N}$, No 14 (julioseptiembre, 1970).

CirL, Alberto. La comunicación politica en America Latina: Algunos de sus problemas. Año II, No 8 (enero-marzo, 1969).

Cunrson, Stephen. La intelligentsia satélitc: Los intelectuales canadicnses frente a los Estados Unidos. Año v, No 18 (abril-junio, 1972).

Clayerie Rodrícuez, Eliodoro L., EcheVERRÍl, Pedro Luis y VILLALBA VIRR, Jovito A. El tratado modificado de reciprocidad comercial entre Venezuela y los Estados Unidos. Año v, No 19 (julio-septiembre, 1972).

Constantroscu, Leontin. Las relaciones Estados Unidos-Comunidad Económica Europea en la perspectiva de la Rueda Nixon. Año vi, NQ 21 (enero-marzo, 1973). 
Cotler, Julio. Crisis política y Populismo Militar en el Perú. N8 12 (enero-marzo, 1970). Año $\mathrm{N}$.

Croner, Claos. Estudios sobre el subdesarrollo colombiano. Comentario critico. Año IV, NQ 14 (julio-septiembre, 1970) .

Didmand, Marcelo. Las posibilidades de una técnica nacional en Latinoamérica (el caso argentino). Año Ix, No 34 (abril-junio, 1976).

Hacia cl cambio del paradigma económico a través de la experiencia de los países en desarrollo. Año $\mathrm{x}$, No 39 (julio-septiembre, 1977).

DFlcado, Carlos. Sobre algunos problemas de la participación en la Revolución Peruana. Año vi, No 21 (enero-marzo, 1973) .

Deyrlerer, Philippe. Francia y la Segunda Guerra del Vietnam. Afio 11, No 6 (julio-septiembre, 1968).

Díaz Alejandro, Carlos F. El Crupo Andino en el proceso de Integración Latinoamericana. Año In, No6 (julio-septiembre, 1968).

Relaciones Norte-Sur: El componente económico. Año x, N9 37 (eneromarzo, 1977).

Echeverrí, Pedro Luis, Clayerie Ropricuez, Heliodoro L., y Villalba VERA, Jovito A. El Tratado modificado de reciprocidad comercial entre Venezuela y los Estados Unidos. Año v, No 19 (julio - septiembre, 1972) .

END, Heinrich. La politica exterior del gobierno Kissinger-Brandt. Año Ir, Ni 7 (octubre-diciembre), 1968).

FAGEN, Richard. La política exterior de los Estados Unidos y el desarrollo đel Tercer Mundo, Año $\mathrm{Ix}, \mathrm{N}$ \% 35 (julio-septiembre, 1976) .

FAÚNDEZ, Julio. El Sistema Interamericano de Seguridad en la política exterior de Estados Unidos. Año III, No 11 (octubre-diciembre, 1969). El presidente de Estados Unidos y la facultad para hacer la guerra.
Año NV, No 15 (octubre-diciembre, 1970).

FERrer, Aldo, Relaciones económicas entre la Comunidad Económica Europea $\mathrm{y}$ Amćrica Latina. Año vr, No 24 (octubre-diciembre, 1973).

$\mathrm{La}$ crisis del sistema monetario Internacional. Un enfoque estructuralista. Año viII, No 30 (abril-junio, $1975)$.

French, Davis, Ricardo. Pacto Andino $y$ Libre Comercio. Año $x$, No 38 (abril-junio, 1977).

Flores de LA PENA, Horacio. Un nuevo modelo de desarrollo. Año $\mathrm{x}, \mathrm{N}^{9}$ 39 (julio-septiembre, 1977) .

FrondizzI, Arturo. El problema nacional de América Latina y ciertos esquemas de integración regional. No 3 y 4 (octubre, 1967-marzo, 1968), Año I.

Fogartr; John, Australia y el problema de las inversiones extranjeras. Año v, No 22 (abril-junio, 1973).

Furtado, Celso, La concentración del poder económico en los Estados Unidos y sus proyecciones en América Latina. No 3 y 4 (octubre, 1967-marzo, 1968), Año I.

El conocimiento económico de América Latina. Año $\mathrm{m}$, No 36 (septiembre-diciembre, 1976).

Proceso y frustración de las reformas agrarias en América Latina. N.os 3 y 4 (octubre, 1967-marzo, 1968), Año I.

Una interpretación estructuralista de la "crisis" actual del capitalismo. Año vır, No 30 (abril-junio, 1975) .

Girvas, Norman, El conflicto de Guyana-ALCAN y la nacionalización de DEMBA. Año v, No 19 (julio-sep* ticmbre, I972).

Teorías de dependencia económica en Eil Caribe y Latinoamérica: un estudio comparativo. Año vr, No 23 (julio-septiembre, 1973).

GrtTincs, John. ¿Tiene China una-política exterior? No 1 (abril, 1967), Año 1. 
Libros sobre la guerra en Vietnam. No 2 (julio, 1967), Año I.

El Ejército Popular de Liberación y

la Revolución Cultural. Año In, NQ 5 (abril-junio, 1968).

La nueva guerra en Indochina. Año rv, NQ 14 (julio-septiembre, 1970).

Godoy, Horacio HI. La integración de América Latina y el proceso del poder mundial. Año II, Ne 7 (octubre-diciembre, 1968).

Los acuerdos entre los Estados Unidos y la Unión de las Repúblicas Socialistas Sovićticas. Año vi, Niq 28 (octubre-diciembre, 1974).

GorT, Richard. El sur de Africa y el fin de la guerra fría. No 1 (abril, 1967), Año I.

E1 Congo a partir de Mobutu. N.os 3 y 4 (octubre, 1967-marzo, 1968), Año $\mathrm{I}$.

La experiencia guerrillera en Bolivia. Año II, No 5 (abril-junio, 1968).

Grant, Bruce. Australia y el Pacífico. Año $v$, No I7 (cnero-marzo, 1972).

Grant, James P. Las naciones de la OPEP: ¿Asociados o competidores? Año virr, No 30 (abril-jalnio, 1975).

Grayson, George W., Jr. Portugal y el Movimiento de las Fucrzas Armadas. Año $1 \mathrm{x}$, No 33 (enero-marzo, 1976).

Guerrero, Mauricio y Sacasti, Francisco. Situación de la ciencia y tecnologia en América Latina. Año vil, No 25 (encro-marzo, 1974).

Halty Carrere, Máximo. ¿Hacia un nuevo orden tecnológico. Año vin, No 32 (octubre-diciembre, 1975).

Hansen, Roger. Relaciones económicas entre los Estados Unidos y América Latina. ¿Bilaterales, regionales o globales? Año vH, No 31 (julio-septiembre, 1975).

Herrers, Amillcar O. La ciencia en el desarrollo de América Latina. Año II, No 5 (abril-junio, 1968).

Herrera, Felipe. Viabilidad de una comunidad latinoamericana. Año r, No 1 (abril, 1967).
La tarea inconclusa: América Latina integrada, Año vr, No 21 (enero-marzo, 1973).

América Latina y el desafio internacional para la educación. Año vin, No 25 (enero-marzo, 1974).

Amćnica Latina y el Tercer Mundo. Año $\mathrm{x}$, N$^{\prime} 40$ (octubre-diciembre, 1977.

Hinsciman, Albert O. Liderazgo, percepción del cambio y subdesarrollo. Año In, No 6 (julio-septiembrc, 1968) .

Hodard, Joseph. La estructura internacional: cuatro versiones. Año vur, No 31 (julio-septiembre, 1975).

Hofmann, Stanley. El estilo norteamericano: su pasado, sus principios. Año III, NQ 9 (abril-junio, 1969) .

Holbrand, Carsten. El papel de las potencias medias en la política internacional. Año $r$, No 17 (eneromarzo, 1972).

Hurtado, Héctor, Pazos, Javier y MAYoBke, Eduardo, El Caribe y Venezuela: integración de la integración. Año vII, No 27 (julio-septiembre, 1974).

Iglesins, Enrique V. Transferencia de recursos en el ámbito internacional. Año Ix, No 34 (abril-junio, 1976). Situación y perspectivas de América Latina. Año $x$, No 39 (julio-septiembre, 1977 ).

Yaraz, José Luis de. ¿Adiós a la teoria de la dependencia? Una perspectiva desde la Argentina. Año 'vII, No 28 (octubre-diciembre, 1974).

IRELAND, Rowan. La Iglesia Cátólica del Brasil: limites del aggiornamento. Año vII, No 27 (julio-septiembre, 1974).

JAGUARIBE, Helio. El equilibrio ecológico mundial y los paises subdesarrollados. Año v, No 17 (enero-marт., 1972).

Los acontecimientos chilenos. Año 
vir, NQ 26 (abril-junio, 1974).

Brasil y la América Latina. Año vir, No 29 (enero-marzo, 1975).

El Vietnam y los Estados Unidos. Año vIII, No 31 (julio-septiembrc, 1975).

El estudio del futuro $y$ de la supervivencia del hombre. Año $x$, No 36 (septiembre-diciembre 1976) .

\pm 1 informe Linowitz $Y$ las relacio. nes Estados Unidos-América. Año $\mathrm{x}$, 15? 40 (octubre-cliciembre 1577).

Joxe, Alain. Hacia una nucva concepción de la seguridad europea. Año I, No 2 (julio 1967).

Cohetes anticolsetes: ¿2Regreso a cscrategias defensivas? Año It, NQ 5 (abril-junio 1968).

Doctrina estratégica $y$ guerras de intervención. Año $n, N^{N} 6$ Gulio. septicmbre 1968).

¿Fin de la prepontlerancia estratégica nortcamericana Año IIr, No 11 (octubre-diciembre 196S).

Joxe, Alain y CADEN 1 , Cccilia. Armamentismo dependiente: Caso latinoamericano, Año Iv, No l. septiembre 1970) .

KaDAr, Bela. Los países pequeños en la economía mundial. Año IV, NQ 16 (enero-marzo 197l).

KAISE, Karl. Una nucva polílica oriental en Alemania. Año II, No S (enero-marzo 1969).

Kaleckr, M. y Kuch, Narcin. Notas sobre los aspectos soc'ales $y^{\prime}$ económi$\cos$ de los "Regímencs Intermeclios", el caso de Bolivia. Año w, № 15 (octubre-diciembre 1970).

KojIma, Kiyoshi, Un área de libre comercio del Pacífico, Año $\mathrm{v}, \mathrm{N} Q 20$ (octubre-diciembre 1972).

KuLA, Marcin y Katlzekt, M. Notas sobre los aspectos sociales $y$ económicos de los "Regímenes Intermedios"; el caso de Bolivia. Año Jv, Ne 15 (octubre-d:ciembre 1970).

LAFER, Celso. Una redefinición del orden mundial $y$ la Alianza Latinoamericana. Perspectivas $y$ posibili- dades. Año vir, No. 31 (julio-septiembre 1975).

Lagos, Gustavo. E1 plan Carter y "La Gucrra de la Energia". Año $x$, NP 40 (octubre-dicicmbre 1977).

LANGLors, Juan Carlos. Una nueva dimensión para los Bancos de Desarollo. Año $\mathrm{x}, \mathrm{N}$ ? 33 (enero-marzo 1976) .

Low'EnTHLL, Richartl. Alemania y el fin del sistema bipolar en la politíca internacional. Año I, No 3 y 4 (octubre 1967-marzo 1968).

Ejércitos y política en América $\mathrm{La}^{-}$ tina. Año $\mathrm{xx}$, 35 (julio-septiembre 1976$)$.

El fin de la presunción hegcmónica. Año $x$, No 37 (encro-marzo $197 i)$.

LUNA, Julio. El desarrollo pesquero y la integración regional. Año $\mathrm{IV}$, No 14 (julio-septiembre 1970).

Miartins, Luciano. Majo de 1968: una revolución nucva e intransitiva. Año III, No 10 (julio-septicmbre 1969).

MArtelakT, Armand. La dependencia de los medios de comunicación de miasas en Chile. Año IV, No. 13 (abrit-junio 1970).

Mayobre, Eduardo, Hurtado, Héctor Y Pazos, Javier, El Caribe y Venezuela: integración de la integración. Año vIr, No 27 (julio-septiembre 1974).

Mertini, Cesarc, La posición internacional de Italia. Oportunidades y tentaciones. Año $v, N^{\circ}$ I7 (eneromarzo 1972).

Mmaty, Eugene B. La cstrategia de los Estados Unidos en el Pacífico Occiclental y el dilema de Micronesia. Año $v$, No 17 (cnero-marzo 1972).

MIJLLAK, T. B. Los Océanos Indico y Pacifico: Algunas consideraciones estratégicas. Año III, No 11 (octubre diciembre 1969).

Mirski, Gueorgui, El papel político del ejército en los paises de Asia y 
Africa. Año IV, No 13 (abril-junio 1970).

Moneta, Juan Carlos. Argentina $y$ Australia: Esqucmas para la cooperación. Año v, NQ 21 (cnero-marzo 1973).

Africa y los grandes actores externos. Año vr, No 27 (julio-septicmbre 1974) .

Moran, Theodore $H$. Nuevo trato a las materias primas. Año $v, N Q 19$ (julio-septiembre 1972) .

Muñoz, Heraldo y SANCHEz, Walter. La Détente y el Sistema Internacio. nal. Año vin, No 32 (octubre-diciembre 1975).

MuÑoz, Heraldo. Dependencia estratégica y no-estratégica: materias primas y relaciones en la perspectiva de la crisis petrolera. Año $\mathrm{Ix}, \mathrm{N} 933$ (enero-marzo 1976).

Murphy, Cornclius F. Jr. Coacción cconómica y tratados desiguales. Año rv, No 14 (julio-scpticmbre 1970).

Naumon, Carlos. Cinco libros sobre Israel. Año n, No 6 (julio-septiembre 1968) .

NrekrRk, Arnold Van. La pendiente de la dependencia: una versión desde afuera. Año v, No 18 (abril-junio 1972) .

América Latina y las Antillas Necrlandesas. Año vr, No 23 (julio-septiembre 1973) .

La sociología latinoamericana: un testimonio epistemológico. Año $1 \mathrm{x}$, No 36 (septiembre-diciembre 1976).

OGExsey, J. C. M. Relaciones canadiense - latinoamericanas, pasadas, presentes $\mathrm{y}$ futuras. Año $\mathrm{v}, \mathrm{N}^{\mathrm{T}}$ i8 (abril-junio 1972).

Ot.pent, Carin. Estudio comparativo sobre zonas pesqueras en el mundo. Año rv, No 13 (abril-junio 1970).

ORREgo Vicuña, Francisco. Dilema en el Grupo Andino. Año III, No 11 (octubre-diciembre 1969) .

Algunos problemas de derecho in- ternacional planteados por la na. cionalización de la industria del cobre en Chile. Año vi, NQ 24 (octubre-diciembre 1973) .

De la crisis de la energía al concepto del patrimonio económico de la humanidad: criterios para reestructurar el sistema económico internacional. Año v'Ir, No 32 (octubre-dicicmbre 1975) .

Las alternativas de América Latina como clase media de las naciones. Año $x$, No 40 (octubre-diciembre 1977) .

ORTuz, Eduardo. Las grancles potencias $y$ la crisis de Nigeria. Año m, $N^{\prime}$ 9 (abril-junio 1969).

Palata, Pedro A. Analisis del Sistema Monetario Internacional. Año virr, No 32 (octubre-dicicmbre 1975).

PALMA VICUÑ , Ignacio. Aportes para un anallsis de la crisis chilena. Año VII, Ni 26 (abril-junio 1974).

Pazos, Javier, Hurtado, Héctor y MaroBre, Eduardo. El Caribe y Venezucla: integración de la integración. Año vir, No 27 (julio-septiembre 1974) .

PEÑa, Félix, El Grupo Andino: un nuevo enfoque de la participación internacional de los países en desarrollo. Año v, No 22 (abril-junio 1973) .

Tendencias y perspectivas de la integración cconómica en América Latina. Año ym, No 29 (eneromarzo 1975).

Pérez Llanh, Carlos E. América Latina y los paises no alineados. Año vi, No 24 (octubre-diciembre 1973). Potencias intermedias o paises mayores? La política exterior de $\mathrm{Ar}$ gentina, Brasil y México. Año vil, No 29 (enero-marzo 1975) .

El legado de Henry Kissinger: algunas implicancias. Año $x$, NQ 37 (enero-marzo 1977).

Petras, James y Rmernsnider, Ncison. Los militares y la modernización del Perú. Año rv, No 13 (abril-junio 1970). 
Petras, James, Venezucla: una década de democracia capitalista. Año IV, Ne 15 (octubre-diciembre 1970).

PINTo, Anibal. Relaciones cconómicas entre América Latina y Estados Unidos: Implicaciones y perspectivas politicas. Año v, No 22 (abriljunio 1973).

Rubeiro, Darcy. El desafio de la marginalidad. Año $\mathrm{W}$, No 16 (encromarzo 1971).

Nucvos caminos de la Revolución Latinoamericana. Año $v$, Ne I8 (abril-junio 1972).

Sabato, Jorge A. Energía Atómica en Argentina. Año Ir, No 7 (octubrediciembre 1968).

EI cambio tecnológico necesario $y$ posible. Año $\mathrm{xx}$, No 36 (septiembrediciembre 1976).

SAcHs, Ignacy. Ecodesarrollo; un aporte a la definición de estilos de desarrollo para América Latina. Año vat, No 25 (enero-marzo 1974).

SAGast, Francisco y Guerrero, Mauricio. Situación de la ciencia y tecnología en América Latina. Año vir, No 25 (encro-marzo 1974).

SAgusti, Francisco R. Autodependencia tecnológica y cooperación entre los páses deI Tercer Mundo. Año Ix, No 33 (enero-marzo 1976).

SalGaDo, Germánico. Integración, conciliación de políticas y diferencias de estructura cconómica. Año $x$, NP 38 (abril-junio 1977).

SÁNCHEz, Walter y MUÑoz, Heraldo. La Détente y el Sistema Internacional. Año vill, No 32 (octubre-diciembre 1975).

SANCHEz, Walter. El Triúnglio Washington-Moscú-Pekin y el proceso de distensión internacional. Año $\mathrm{IX}, \mathrm{N}^{9}$ 35 (julio-septicmbre 1976).

SATHYAMURTHY, T. V. Las relacioncs internacionales asiáticas: perspectivas contemporáncas. Año IV, NQ 15 (octubre-diciembre 1970).
Schmrteter, Philippe C. La portugalización de Brasil. Año v, NQ 19 (julioseptiembre 1972).

Sepúlveda, Alberto, El militarismo desarrollista en América Latina. Año xv, No I5 (octubre-diciembre 1970).

SIgmund, Paul E. El bloqueo invisible y la caida de Allende. Año vin, $N^{T}$ 26 (ábril-junio 1974).

Silya Castro, Raúl. Juan Egaña, precursor de la integración latinoamericana. Año II, NO 7 (octubre-diciembre 1968).

Sulva Mrchelend, José A. Tendencias recientes en la politica mundial. Año vI, No 23 (julio-septiembre 1973).

SNow, Peter G. Desarrollo económico y Seguridad Nacional en el Régimen Militar Argentino. Año $v$, No 20 (octubre-diciembre 1972).

Sunker, Osvaldo. Política nacional de desarrollo y dependencia externa. Año I, No I (abril 1967).

La tarea politica y teórica del planificador en América Latina. Año II, NP 8 (enero-marzo 1969):

Esperando a Godot: América Latina ante la nueva administración republicana de los Estados Unidos. Año III, No 9 (abril-junio 1969).

La Universidad Latinoamericana ante el avance científico y técnico; algunas reflexiones. Año iv, No 13 (abril-junio I970) .

Capitalismo transnacional y desintegrạción nacional en América Latina. Año $\mathrm{rv}$, No 16 (enero-marzo 1971).

El desarrollo de la teoría del desarrollo. Año $x$, NQ 40 (octubre-dicicmbre 1977).

TADIC, Bojana. No-alineación: un vistazo histórico y conceptual. Año In, No 10 (julio-septiembre 1969).

Tertelbom, Sergio. Los países del Pacífico Sur y el mar tcrritorial. Año rv, Ne I3 (abril-junio 1970). 
Thomas, Hugh, La Revolución Cubana y sus ráices históricas. Año I", No 16 (enero-marzo 1971).

Thomson, James C. Jr. Vietnam: un caso clínico. Año in, No 7 (octubrediciembre 1968).

TIRonr, Ernesto. Las estrategias nacionales de desarrollo y la integración de los Países Andinos. Año $\mathrm{x}, \mathrm{N}$ O 34 (abril-junio 1976).

La Decisión 24 sobre capitales extranjeros en el Grupo Andino. Año $x$, No 38 (abril-junio 1977).

'Tomassini, Luciano. La misión imposible del presidente Nixon. Año IY, No 12 (cnero-marzo 1970).

Implicaciones internacionales del deterioro ecológ:co. Año $\mathrm{v}, \mathrm{N}$ Q 18 (abril-junio 1972).

Tendencias favorables o adversas a la formación de un sistema regiona! latinoamericano. Año vir, NQ 29 (enero-marzo 1975) .

Falencias y falacias: notas sobre el estudio de las relaciones Norte-Sur. Año $x$, No 40 (octubre-diciembre 1977).

Torres-RIVAs, Edelberto. Desarrollo, integración $y$ dependencia en Centroamérica. Año $\mathrm{V}$; NQ 12 (eneromarzo 1970).

ToYNaEe, Arnold. El estudio de la his. toria contemporánea. Año I, No 1 (abril 1967).

Uslar Pietri, Arturo. Lo especifico de! hombre latinoamericano. $A$ ño $\mathrm{rx}$, No 36 (septiembre-diciembre 1976).

VAiLDEs Subercaseaux, Gabriel. Situación del Grupo Andino en el contexto Iatinoamericano e internacional. Año $\mathrm{x}$, NQ 38 (abril-junio 1977) .

VAN DaM, André. El triunfo del cabalio. Año. $\mathrm{Ix}$, NQ 34 (abril-junio 1976) .

VéLiz, Claudio. E1 Instituto de Estudios Internacionales. Año I, No 1 (abril 1967).
Centralismo, Nacionalismo e Integración. Año III, NQ 9 (abril-junio 1969) .

Cambio $y$ continuidad: El Pacto Andino en la historia contemporánea. Año $\mathrm{r}$, No 16 (enero-marzo 197i) .

Errores $y$ omisiones: notas sobre la polftica exterior de los países de América Latina durante los ultimos diez años. Año $x$, No 40 (octubrediciembre 1977).

VERnant, Jacques. El mundo, Europa y Francia. Año t, No 2 (julio !967).

VIL, S, Carlos María y AcostA, Mercedes, Santo Domingo y Checoslovaquila en la política de bloques. Año II, No 8 (encro-marzo 1969).

VILLALAA Verd, Jovito A., Clatyerie Ronríguez, Heliodoro L. Y EchEVEkRís, Pedro Luis. El Tratado modificado de reciprocidad comercial entre Venezuela y los Estados Unidos. Año v, No 19 (julio-septiembre 1972) .

VhLAGRiN KraAier, Francisco. Mecanismos de regulación internacional de productos básicos. Año v, No 23 (julio-septiembre 1973) .

WaLLis, Victor. La experiencia de Brasil con una politica exterior independiente. Año 1 , No 2 (julio 1967).

Watkins, Mclville H. Canada: industria $y$ propicdad extranjera. Año u, No 10 (julio-scptiembre 1969).

WeRTHLIM, W. F. Indonesia antes $y$ después del golpe de Untung. Año I, NQ $3 \mathrm{y} 4$ (octubre 1967-marzo 1068).

WhHelm, Manfred. La politica exterior chilena en el Grupo Andino. Año $x$, NQ 38 (abril-junio 1977).

Younger, Kemeth. El papel de Gran Bretaña en la polltiça internacional. Año I, No 2 (julio 1967). 